\title{
Environment-Assisted-Cracking Under Measured and/or Controlled Electrochemical Potential
}

\author{
Ajit Roy
}

November 7, 1997

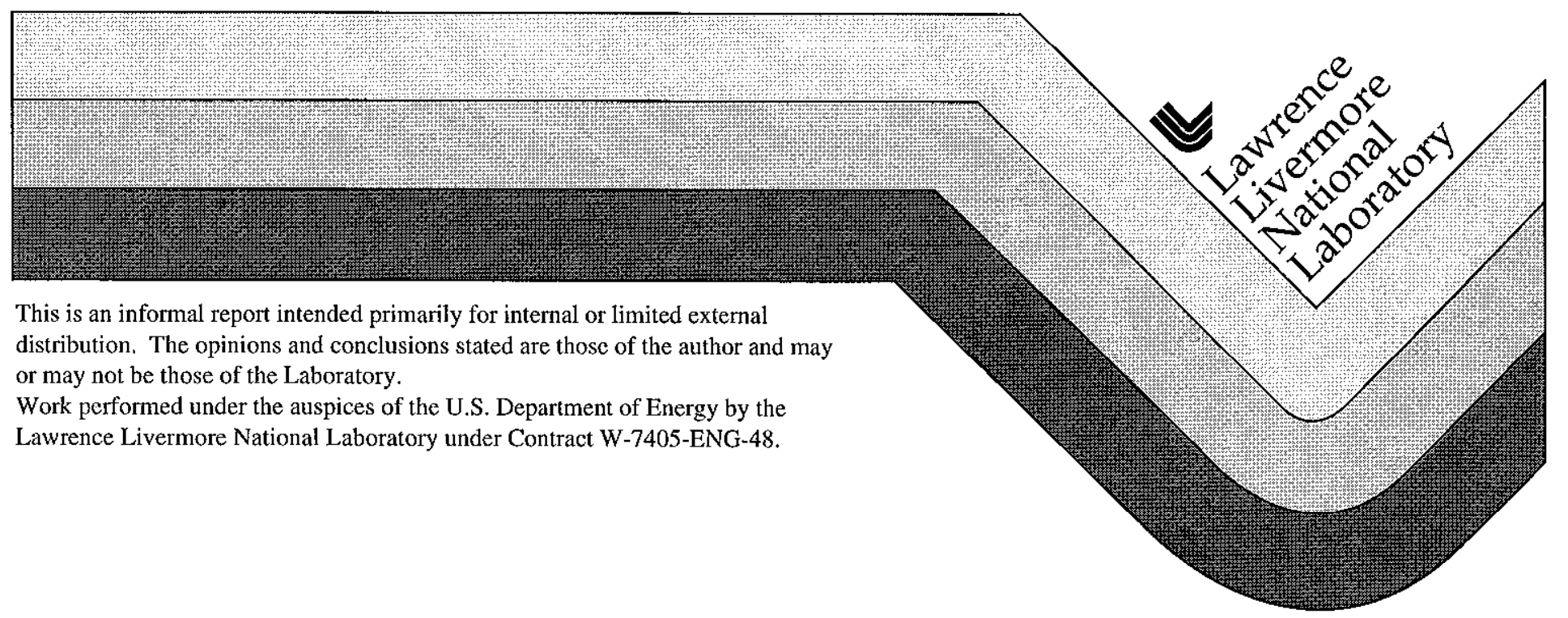




\section{DISCLAIMER}

This document was prepared as an account of work sponsored by an agency of the United States Government. Neither the United States Government nor the University of California nor any of their employees, makes any warranty, express or implied, or assumes any legal liability or responsibility for the accuracy, completeness, or usefulness of any information, apparatus, product, or process disclosed, or represents that its use would not infringe privately owned rights. Reference herein to any specific commercial product, process, or service by trade name, trademark, manufacturer, or otherwise, does not necessarily constitute or imply its endorsement, recommendation, or favoring by the United States Government or the University of California. The views and opinions of authors expressed herein do not necessarily state or reflect those of the United States Government or the University of California, and shall not be used for advertising or product endorsement purposes.

This report has been reproduced directly from the best available copy.

Available to DOE and DOE contractors from the

Office of Scientific and Technical Information

P.O. Box 62, Oak Ridge, TN 37831

Prices available from (423) 576-8401

Available to the public from the National Technical Information Service

U.S. Department of Commerce 5285 Port Royal Rd. Springfield, VA 22161 
University of California

Lawrence Livermore

No.: $\quad$ E-20-45

National Laboratory

YUCCA MOUNTAIN PROJECT

Activity Plan

Subject:

Environment-Assisted-Cracking under Measured and/or Con-

trolled Electrochemical Potential

Revision: $\quad 0$

Change Notice: $\mathrm{CN}-1$

Page: $\quad 1 \quad$ of 9

AUTHOR:

Ajit Roy

Training Required:

Comments:

Editorial text change only.

REVISION HISTORY

Bev. No. CN No. Effective Date Description of Revision/CN

0

$10 / 28 / 97$

Original issue.

0

$E-20-45-0-1 \quad 11 / 07 / 97$

Minor editorial text change

only, affects page 2 of 9.

APPROVALS:

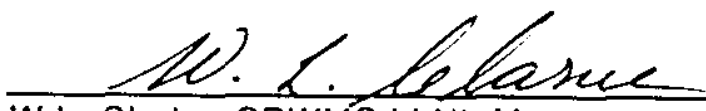

W.L. Clarke, CRWMS LLNL Manager

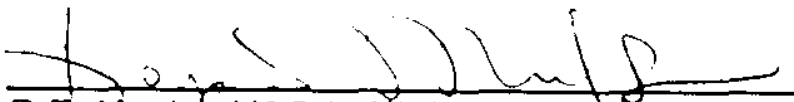

R.E. Monks, M\&O LLNL Engineering Assurance Manager 


\title{
ACTIVITY PLAN
}

\begin{abstract}
E-20-45
Environment-Assisted-Cracking under Measured and/or Controlled Electrochemical Potential
\end{abstract}

\author{
Ajit Roy \\ Lead Principal Investigator \\ YMP WBS Element 1.2.2.5.1 \\ Metal Barrier Task \\ Lawrence Livermore National Laboratory
}

October 08, 1997 


\subsection{INTRODUCTION}

This activity plan is prepared in accordance with Lawrence Livermore National Laboratory (LLNL) Yucca Mountain Project procedure 033-YMP-QP 3.0 entitled "Scientific Investigation Control." This plan is written for activity E-20-45 entitled "Environment-Assisted-Cracking under Measured and/or Controlled Electrochemical Potential," which is a part of the Scientific Investigation Plan (SIP) "Metal Barrier Selection and Testing" (CN SIP-CM-01, Rev.3). This activity falls under Work Breakdown Structure (WBS) section 1.2.2.5.1 (Metal Barriers Task) of WBS 1.2.2.5 (Waste Package Materials) under the Yucca Mountain Site Characterization Project.

\subsection{ACTIVITY OBJECTIVES AND SCOPE}

Longer-term stress corrosion cracking (SCC) experiments, described in the activity plan E-20-56, are well underway at LLNL to evaluate the SCC susceptibility of candidate corrosion-resistant inner container materials in a $90^{\circ} \mathrm{C}$ acidic brine containing 5 weight percent ( $\mathrm{wt} \%) \mathrm{NaCl}$ using fatigue-precracked wedge-loaded double-cantilever-beam (DCB) specimens. The results ${ }^{(1)}$ of a recent localized corrosion study have revealed that the propensity to pitting and crevice corrosion in susceptible alloys is characterized by "critical potentials" obtained from the cyclic potentiodynamic polarization (CPP) experiments described in the activity plan E-20-43/44. It is also well known that the tendency to SCC can be influenced by the electrochemical potential. But the role of electrochemistry in SCC has not been explored to a large extent. Therefore, the proposed activity is aimed at evaluating the SCC behavior of susceptible container materials under measured and/or controlled electrochemical potential in repository-relevant environments using DCB and slow-strain-rate (SSR) test specimens. The magnitude of the controlled potential will be selected based on the measured "critical potentials" obtained from the CPP experiment performed earlier in a similar environment. The resultant data will enable the mechanistic understanding of the cracking process in materials of interest under the synergistic influence of applied stress and corrosive medium, which will be utilized in developing and validating the SCC models for long-term performance assessment.

\subsection{ACTIVITY DESCRIPTION}

\subsection{Test Materials}

A list of materials recommended for testing is shown in Table 1. This include iron-nickelchromium-molybdenum (Fe-Ni-Cr-Mo) alloys 825, G-3, G-30; Ni-Cr-Mo alloys C-4, 625 and $\mathrm{C}-22$; and a titanium alloy Ti Grade-12. Corrosion-allowance A 516 steel is also included in this testing program. For SCC tests using DCB specimens, a major effort will be focused on alloys C-22 and 625 , and Ti Grade- 12 . On the other hand, SSR tests will be performed on all materials listed in Table 1. The materials listed in Table 1 may be modified later as work progresses in the Waste Package Design and Waste Package Materials areas. Any modification made in this list of test materials will be noted in the Scientific notebook. 


\subsection{Test Environments}

The initial test environments will be deaerated $90^{\circ} \mathrm{C}$ acidic brines of various $\mathrm{NaCl}$ concentrations (1-5 wt\%). Deaeration by bubbling an inert gas through the test solution is aimed at controlling the oxygen content. The selection of acidic brines is based on the results $^{(1)}$ of a most recent electrochemical study that showed the maximum localized corrosion susceptibility of some of the tested materials in similar environments. The test environments may be modified later to evaluate the effects of $\mathrm{pH}$, temperature and other ionic species on the cracking behavior of materials of interest. Test solutions will be made from distilled water and reagent grade chemicals following standard laboratory practices.

\subsection{Experimental Procedure}

The susceptibility to SCC will be evaluated by using both DCB and SSR techniques. The experimental details for SCC tests using DCB specimens have been described in the activity plan E-20-56, and therefore, will not be repeated here. However, no attempt has yet been made to monitor the corrosion or open circuit potential $\left(\mathrm{E}_{\text {corr }}\right)$ of the wedgeloaded DCB specimen while exposed to the test solution. Future tests, proposed in this activity plan, will attempt to periodically measure the $E_{\text {con }}$ value over the entire test duration by placing a reference electrode close to the DCB specimen. The resultant crack extension in an individual specimen will then be correlated to the measured $\mathrm{E}_{\mathrm{cor}}$ value.

During SSR testing, a smooth tensile specimen (Figure 1) will be continuously strained in tension until fracture, in contrast to the more conventional SCC testing conducted under a sustained load condition. The application of slow dynamic straining $\left(10^{-6}\right.$ to $10^{-8}$ $\mathrm{in} / \mathrm{in} / \mathrm{sec}$ ) to the tensile specimen will facilitate cracking in materials which may not exhibit cracking under constant load or may take a prohibitively long time for crack initiation. Thus, the tensile specimen in SSR testing can undergo fast failure in a ductile manner if $\mathrm{SCC}$ does not occur, or prematurely in a brittle manner if SCC occurs.

As mentioned earlier, electrochemistry may play a significant role in characterizing the $\mathrm{SCC}$ behavior of materials of interest. Accordingly, the $\mathrm{E}_{\mathrm{corr}}$ value of the test specimen will be measured with respect to a $\mathrm{Ag} / \mathrm{AgCl}$ reference electrode contained inside an autoclave made of a suitable corrosion-resistant alloy, and capable of maintaining test temperatures of at least $100^{\circ} \mathrm{C}$. The tensile specimen immersed into the test solution will be pulled in tension using an Instron testing machine. By knowing the $\mathrm{E}_{\text {corr }}$ value, and the measured critical potentials from previous CPP experiments, the magnitude of the controlled electrochemical potential $\left(\mathrm{E}_{\text {cont }}\right)$ will be selected. This potential will be applied to the tensile specimen under potentiostatic control during the entire straining period. A graphite rod will be used as a cathode during the potentiostatic polarization.

In conventional static SCC tests, the cracking susceptibility is commonly expressed in terms of either a threshold stress below which cracking does not occur in an arbitrary period of time, or the time to failure at a given applied stress. With SSR tests, however, similar approaches can not be made since the test specimen is subjected to a continuously changing stress during straining. Therefore, the cracking tendency at a given strain rate 
can be characterized by a number of readily measurable and quantifiable parameters obtained from the load-deflection curve and the examination of the broken specimen.

Since SCC is usually associated with relatively little macroscopic plastic deformation during crack propagation, the ductility parameters such as the percent elongation (El\%) and the reduction in area (RA\%) are very useful in expressing the cracking propensity. In addition, the true fracture stress $\left(\sigma_{\mathrm{f}}\right)$ obtained from the load-deflection curve can also characterize the extent of cracking tendency.

Attempts will be made to determine an average crack growth rate from the broken test specimen. The length of the deepest secondary crack along the surface of the gage section will be measured from the polished metallographic mount of two broken halves of the specimen. The morphology of cracking (intergranular versus transgranular) will also be established from the metallographic evaluation. By knowing the length of the deepest secondary crack (a) and the total time-to-failure (TTF $=t$ ), the average crack growth rate (da/dt) will be determined. Both da/dt and $\sigma_{\mathrm{f}}$ will be correlated to the measured or applied electrochemical potential. Similarly, El\% and RA\% will be correlated to the electrochemical parameters. The following parameters will be available from the SSR testing:

$\begin{array}{ll}\text { - } & \mathrm{E}_{\text {corr }} \text { and } \mathrm{E}_{\text {cont }} \\ \text { - } & \text { Maximum load }\left(\mathrm{P}_{\max }\right) \\ \text { - } & \text { Failure load }\left(\mathrm{P}_{\mathrm{f}}\right) \\ \text { - } & \sigma_{\mathrm{f}} \\ \text { - } & \mathrm{TTF} \\ \text { - } & \mathrm{R} \% \\ \text { - } & \mathrm{da} \% \\ \text { - } & \text { Metallurgical microstructure } \\ \text { - } & \text { Fracture characteristics }\end{array}$

3.4 Major Equipment Need

- An Instron Testing Machine

- An Autoclave

- $\quad$ An EG\&G Model 283 Potentiostat

- An IBM-compatible PC

\subsection{Technical and Readiness Reviews}

No additional formal Readiness Review (QP 2.6) and Technical Review (QP 2.4) are planned for this activity. 


\subsection{Hold Points}

The operation of the testing facility will be monitored on a continuous basis by the Lead Principal Investigator (PI) to ensure that the work is proceeding according to this activity plan. If significant unanticipated problems arise, the PI will inform the Technical Area Leader (TAL). A joint decision will be made about the future course of action.

\subsection{Special Training/Qualification Requirements}

Qualifications of the PI and technicians are specified by the TAL in accordance with 033YMP-QP-2.10 "Qualification of Personnel". A PI shall have a Ph.D. or equivalent in metallurgical engineering or corrosion engineering, with substantial experience in related fields. Technical support staff shall have substantial experience in mechanical, electrical, electrochemical, and corrosion instrumentation and techniques. Only personnel trained to appropriate quality procedures and any other procedures of the Yucca Mountain Site Characterization Project will be allowed to participate in this activity. Assignment of personnel may change with time. Names of personnel authorized to perform the experimental work in this activity will be given in the appropriate scientific notebook. The current position descriptions, management certifications and QA training records will be maintained for each person identified in the scientific notebook.

\subsection{Quality Assurance Program}

This activity is to be conducted in support of "Metal Barrier Selection and Testing," as outlined in CN SIP-CM-01, Rev.3. This testing program will be conducted subject to the provisions of all applicable quality assurance procedures.

\subsection{Activity Close-out}

As with all other activities in the Metal Barriers task, the major reporting channel is through periodic revision of the Engineered Materials Characterization Report or EMCR, which is Activity E-20-39 in CN SIP-CM-01, Rev.3. Supporting documentation such as scientific notebook and technical paper review comments will be retained by the appropriate individual (PI or technical support personnel) until the document package is transferred to the LLNL/YMP Local Records Center at the conclusion of these activities. No additional or special activity close-outs are planned.

\subsection{PRECISION AND ACCURACY}

\subsection{Calibration Requirements}

Confirmatory polarization experiment will be performed according to the ASTM Standard G 5-94 $4^{(2)}$ using Model 283 potentiostat at the beginning of a series of controlled potential SSR tests. The procedure described in this ASTM standard is a self-calibration or confirmation not only of the potentiostat but also of the external circuit. If the series 
of experimental runs exceeds 20 , then another confirmatory test will be performed before the 21 st run. Calibration curves of this system shall be documented in the scientific notebook.

Reference electrodes will not have any calibration requirements. However, the reference electrodes will be inspected frequently for electrolyte level, blockage by gas bubbles, and obvious signs of deterioration. If in doubt, the reference electrode will be replaced by a new one.

The Instron testing machine will be calibrated annually by the manufacturer. The autoclave temperature will be continuously monitored by using a thermocouple. The autoclave will also be checked to prevent the loss of liquid during the course of testing. Solution $\mathrm{pH}$ will be measured using standard laboratory $\mathrm{pH}$ meters which will be calibrated with use of known buffer solutions just prior to use and following the manufacturer's recommended procedure given in the operating manual. Any doubt about the $\mathrm{pH}$ meter is readily resolved by measuring standard $\mathrm{pH}$ buffer solutions.

\subsection{Sources of Uncertainty and Error to be Controlled and Measured}

Random variations in alloy composition, metallurgical microstructure and surface finish of test specimens may slightly influence the test results. However, efforts will be made to get test specimens machined from similar heats of materials having very similar metallurgical properties. It is expected that the calibrations and replications planned will control the effects of any conditions that could adversely affect the test results.

\subsection{IN-PROGRESS DOCUMENTATION}

Documentation to be generated during the conduct of this activity will include scientific notebooks, and may also include data record sheets, raw data, progress reports, and the final report.

Reporting of the results of this activity will occur on a regular or periodic basis as determined by the schedule of project deliverables. The results will also be reported as revisions to the EMCR. In addition, topical LLNL reports (UCRL series) will be prepared on parts of this activity.

\subsection{INTERFACES}

The information obtained from this experimental activity will assist activities in the following technical areas, and copies of the written reports resulting from this activity will be distributed to the individuals listed below:

1. Metal Barrier Selection and Testing (SIP-CM-01) R. D. McCright, TAL, Engineered Barrier Materials

2. Waste Package Performance Assessment Activities (SIP-PA-2) W. Halsey, TAL, Performance Assessment 


\subsection{SCHEDULE}

The schedule is subject to funding. The most recent version of the Yucca Mountain Project PACS budget and schedule will apply.

\subsection{SPECIAL CASES}

No subcontractors will be involved in this activity.

\subsection{REFERENCES}

1. A. K. Roy et al., "Effect of Environmental Variables on Localized Corrosion of High-Performance Container Materials," LLNL Report UCRL-JC-125329, January 1997, presented at the 5th Int. Conf. on Nuclear Engineering, Paper No. ICONE5-2093, May 1997, Nice, France.

2. ASTM Designation: G 5-94, "Standard Reference Test Method for Making Potentiostatic and Potentiodynamic Anodic Polarization Measurements," American Society for Testing and Materials 1995 Book of Standards, Vol. 03.01, pp. 48-58, ASTM, Philadelphia (1995).

\subsection{APPENDIX}

There are no appendices.

\section{Table 1}

List of Materials Recommended for Testing

Commercial Name

Alloy 825 , Incoloy 825

Hastelloy Alloy G-3

Hastelloy Alloy G-30

Alloy 625, Incoloy 625

Hastelloy C-4, Alloy C-4

Hastelloy C-22, Alloy C-22

Titanium Grade-12

Carbon Steel $\underline{\text { UNS Number }}$

N08825

N06985

N06030

N06625

N06455

$\mathrm{N} 06022$

R53400

K01800

\section{ASTM Number}

B 425

B 581

B 581

B 443

B 575

B 575

B 265 Gr 12

A $516 \mathrm{Gr} 55$ 


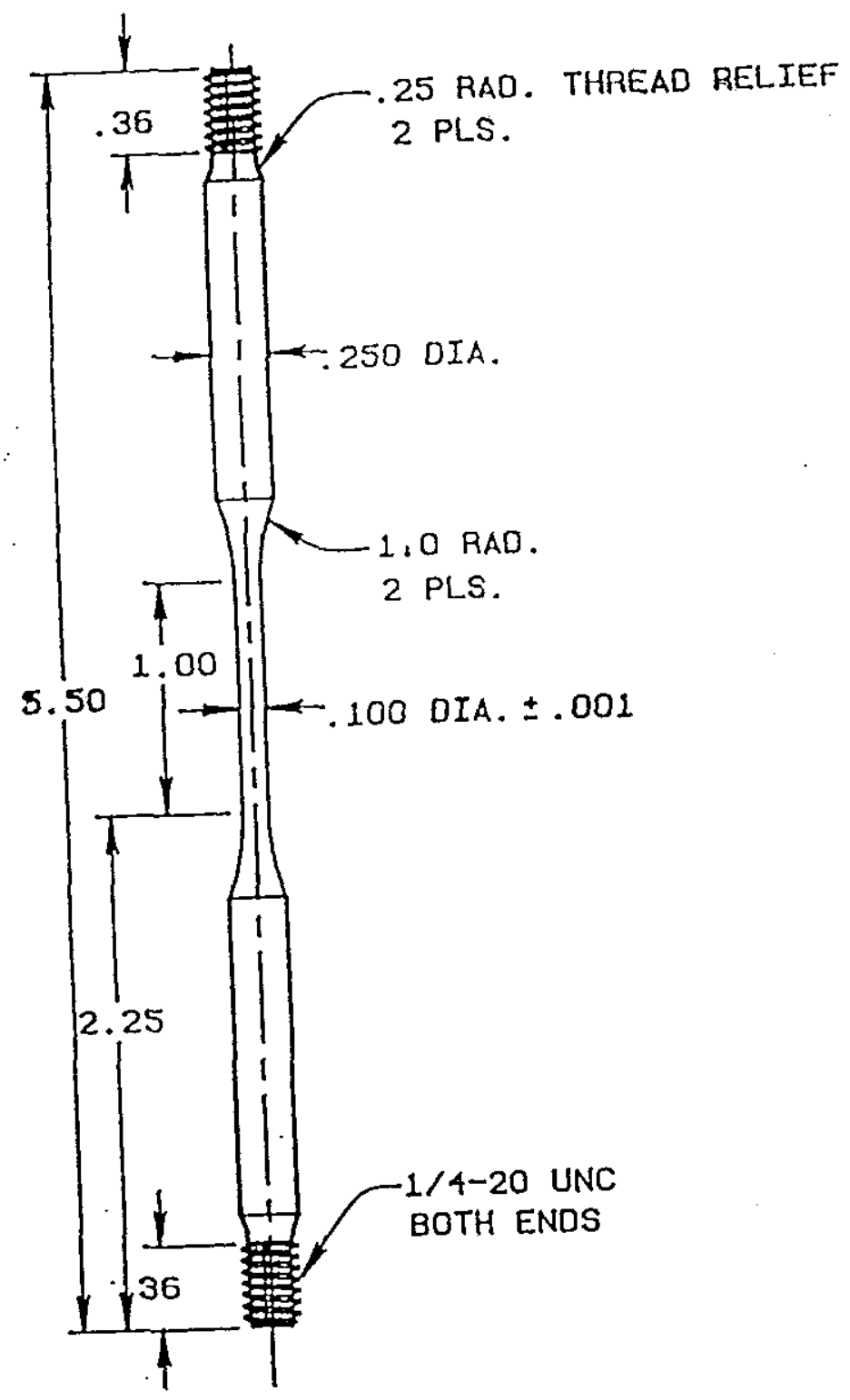

Figure 1. SSR Test Specimen 